\title{
Thermal Process for Enhancing Mechanical Strength of PLGA Nanoparticle Layers on Coronary Stents
}

\author{
Jae-ryang Joo, Hye Yeong Nam, So Hee Nam, Insu Baek, and Jong-Sang Park \\ School of Chemistrv \& Molecular Engineering. Seoul National Lniversit, Seoul 151-747. Korea \\ ${ }^{\star}$ E-mail: pfjsparkíaplaza.snu.ac.kr \\ Received June 5. 2009, Accepted Julv 14. 2009
}

\begin{abstract}
Poly (lactic-co-glycolic acid) (PLGA) nanoparticles loading paclitaxel have been deposited on coronary stents by self-assembling properties of colloidal particles. The layers of the nanoparticles were enhanced to a sufficient nechanical strength by a thennal process under the proper temperature and humidity conditions. In vitro release studies proved the controlled paclitasel release of the nanoparticle lavers. This technique gives rise to a new range of applications for nanoparticles and drug-eluting stents.
\end{abstract}

Key Wonds: Stent. Paclitaxel. PLGA. Nanoparticle. Thermal process

\section{Introduction}

Coronary artery disease (CAD) is one of the most common conditions in the developed world nowadays. $\mathrm{CAD}$ patients have been able to receive percutaneous transluminal coronary angioplasty (PTCA) to reopen flow in their closed vessels for the past several years. ${ }^{2}$ The stent, an intravascular scaffold device. was developed and has had a notable effect to prevent re-narrowing which resulted from elastin re-coiling and tunica media contraction. ${ }^{3,4}$ Drug-eluting stents (DES) are secondgeneration devices to deal with another new obstacle: restenosis. ${ }^{56}$ Drug-eluting stents have shown remarkable results in several clinical trials. ${ }^{-9}$ However. they can result in several biochemical responses like thrombosis, inflammation and neointimal hyperplasia-reactions to the presence of the stents as alien materials. ${ }^{\text {jo. } 11}$ Many companies and researchers have offered and tested a range of new stents which were coated with anti-inflammatory antiproliferative anti-migratory or pro-endothelial drugs to inhibit restenosis. ${ }^{13-14}$ Paclitaxel (Ptx, Taxol $^{B}$ ) is one of the anti-cancer dnigs. ${ }^{15.16}$ It interferes in the formation of microtubules at the cell-dividing stage so that cells cannot proliferate. ${ }^{1 ?}$ Studies using stents which release paclitaxel have demonstrated a considerable decrease in the extent of in-stent restenosis. ${ }^{18.19}$

Poly (lactic-co-glycolic acid) (PLGA) is one of the biocompatible poly mers and has an ester bond-backbone. It has been used in various medicinal applications. ${ }^{2(1,21}$ Moreover, the polymeric properties of PLGA are very important as a drug-reserving matrix on stents. PLGA is an amorphous polyester and shows a glass transition point $\left(T_{\mathrm{g}}\right)$ at $40 \sim 55^{\circ} \mathrm{C}$. ${ }^{2-}$ This characteristic allows an increase in the mechanical strength of PLGA polymer layers with thermal processing.

In this study, we introduced polymer nanoparticles (NPs) for a drug delivery system. ${ }^{23}$ Poly mer nanoparticles have been applied to pharmaceutics for controlled drug delivery $4-1$ ? Poly(vinyl alcohol)-graft-PLGA nanoparticles were shown to exhibit very important results for the local delivery of paclitavel in a recent report. ${ }^{28}$ The drug molecules must pass through a shell constnicted of entangled polymer chains to come out. so the rate of release can be regulated.

\section{Materials and Methods}

Materials. Poly' (lactic-co-glycolic acid) [PLGA (RESOMER' ${ }^{\text {'E' }}$ RG $504 \mathrm{H}$ ). 50:50. Mw 48.000. i.y. $0.45 \sim 0.60 \mathrm{dL} / \mathrm{g}$ in chloroforml was obtained from Boehringer Ingelheim (Germany). Paclitaxel was purchased from Samyang Genex Co. (ROK). Polyvinyl alcohol (PVA. Mw 30,000 - 70.000) was purchased from Sigma Chemical Co. (St. Louis. Mo. USA). Bare metal stents were obtained from Humed (ROK). The organic solvent dichloromethane/methy lene cliloride (MC) was "Baker Allalyzed' HPLC solvent. Distilled water produced by Millipore (Millipore Corporation) was used throughout. All other reagents were of analytical grade and were used without further purification.

Preparation of PLGA Nanoparticles Entrapping Paclitaxel. PLGA and Paclitavel were dissolved in methylene chloride and the methylene clloride solution was poured in $0.2 \%(w / v)$ polyvinyl alcohol (PVA) aqueous solution. An ultrasonic processor (VCX 600 Watt Vibracell: Sonic \& Materials, Danbury. CT) formed an o/w emulsion. The resulting emulsion was stirred for 3 hours at room temperature under reduced pressure to evaporate the organic solvent. After renoving the organic solvent the resulting aqueous suspension particles were centrifiged and re-suspended in distilled water prior to lyophilizing.

Mouphology Obsevation. The morphological examinations of PLGA nanoparticles and their layers which deposited on the stents were performed by scanning electron microscope (SEM. JSM 840-A. Japan). Samples of the above and of nanoparticlecoated stents were platinum coated using a sputter coater.

Nanoparticle Deposition Method Procedure. Nanoparticles were deposited by RST method. ${ }^{3(1}$ Briefly. the suspension of the particles was concentrated to a high density. A stent was immobilized and a ring was set on the stent. Droplets of the concentrated suspension were injected between the stent and the ring. When the ring was moved up and down over the stent the nanoparticles in the suspension were deposited onto the surface of the stent at the wedge where the meniscus met the surface. ${ }^{31}$ The remaining suspension was removed by centrifugation and the stent was dried in a desiccator.

Thermal Processing. PLGA nanoparticle-coated stents were 
heated in a temperature-controllable drying oven (Sangwoo Tech. ROK) for the thermal process (TP). The temperature was $46^{\circ} \mathrm{C}$. The dry conditions were established in a glass chamber with dehydrated air and the humid conditions at the set temperature. The stents were fixed vertically

Mechanical Strength Tests. The mechanical properties of PLGA nanoparticle laýers deposited on stents were evaluated by two simplified strength test methods. The tensile strengths of the nanoparticle layers were estimated by expanding the stent with a balloon catheter. One of the coated stents was installed on a slurunken balloon of a catheter and the balloon was fully expanded ( $10 \mathrm{~atm}$ ). The frictional strengths of nanoparticle layers were estimated by passing them through a figure eight shaped curved tube filled with phosphate buffer saline at $37^{\circ} \mathrm{C}$ as a model of an artery. One of the coated stents was installed on a balloon catheter and passed through the tube at a velocity of $25 \mathrm{~cm} / \mathrm{s}$. This reciprocating process was repeated 3 times. The morphologies of the nanoparticle layers on the expanded or nibbed stents were inspected with SEM.

In Vitro Release Studies. Each stent was immersed in a 15 $\mathrm{mL}$ centrifuge tube containing $5 \mathrm{~mL}$ PBS (pH 7.4) and also containing $0.05 \%(w / v)$ Tween $20^{B}$. The tube was kept in a hybridization incubator that was rotated at a constant rate of $8.5 \mathrm{rpm}$. The temperature was kept constant at $37^{\circ} \mathrm{C}$. The buffer solution was replaced with fresh one at given time intervals. The collected buffer solution was filtered with a $0.2 \mu \mathrm{m}$ syringe filter and analyzed by a reversed phase high-performance liquid cluromatography (RP-HPLC) system (Agilent 1100 Series. USA). Separation was achieved by using a reversed-phase column (300Extend-C 18,4.6 × $150 \mathrm{~mm}$. Agilent. USA) thermostated at $40^{\circ} \mathrm{C}$ and with the flow rate of the mobile phase set at $1.0 \mathrm{~mL} / \mathrm{min}$. The mobile phase composition was $60: 40$ ( $/ / v)$ of water and acetonitrile, and a UV detector set at $242 \mathrm{~nm}$.

\section{Results and Discussion}

Enhancing Mechanical Strengths of Nanoparticle Layers by Themal Process. The surfaces of the stents were observed with a scanning electron microscope (SEM) after nanoparticle deposition. The SEM images (Figure 1) showed that nanoparticles were deposited over the surface of the stents uniformly. The layers had over a micrometer of stratified structure throughout the struts. The particles were closely packed along the plane and the perpendicular.

The mechanical strengths of the nanoparticle layers were not enough to withstand the expanding and the nibbing tests (Figure $2 \mathrm{~A}-\mathrm{B}$ ). The simply deposited ranoparticle layers cracked

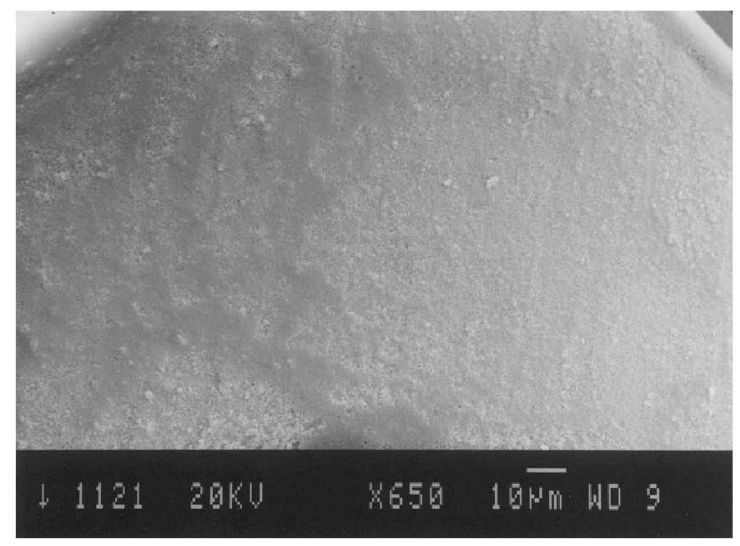

Figure 1. SEM images of PLGA nanoparticle-coated stents.

hard and peeled off. These will be the main problems of the drug loss during the PTCA operations. resulting in poor remedial results. The thermal process (TP) was designed to enhance the mechanical strengths of the PLGA nanoparticle layers with heating and moisturizing. According to the results of the damp TP (Figure 2 C-D), the mechanical strengths of the PLGA nanoparticle layers were improved enough and could endure the expanding and nubbing tests. The nanoparticles maintained the morphologies as particles during the thernal process (Figure $2 \mathrm{E}$ ). The PLGA nanoparticle layers. however, showed unsatisfactory enhancement in the dry TP condition. It was assumed that this difference would result from the nicro-wet enviromment between the nanoparticles. The polymer chains are entangled and project at the surfaces of the polymer particles. When heated, these chains of neighboring particles move dymanically and become entangled with each other. The lumid conditions could fonm the water phase between the polymer particles leading to an acceleration of the entanglement of the polymer chains. The polymer chains could move more dynamically in the micro-wet emvironment between the polymer particles than in a dry environment despite the hydrophobic characters of the chains. These effects enhanced the mechanical strengths of the polymer nanoparticle layers enough to be stable in the PTCA operations.

In Vitro Release Profiles of Paclitaxel-loaded Stents. The thermal process did not alter the release profiles even although it enhanced the strength of the nanoparticle layers. The paclitaxel release displayed sinular patterns among different groups which were underwent the thermal process with various times (Figure 3). It seems that the thermal process did not affect the PLGA shells of the nanoparticles but the surfaces which were

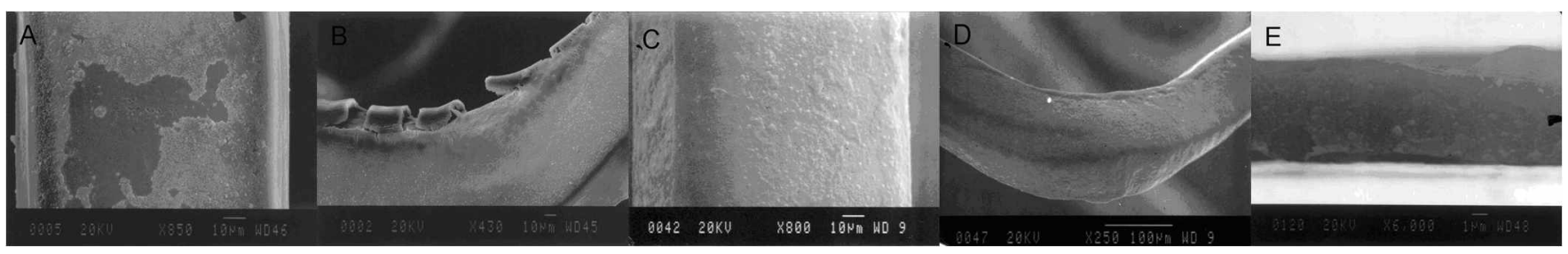

Figure 2. SEM inages of PLGA nanoparticle layers on stents after mechanical strength tests. (A) control-rubbing, (B) control-expanding, (C) damp I'P-rubbing, (D) damp I'P-expanding, (E) damp I'P-a cross section of a nanoparticle layer. 


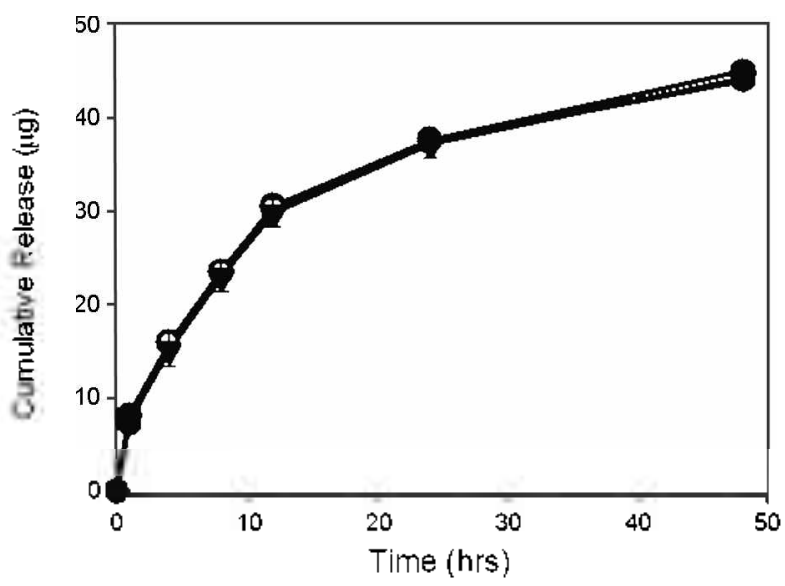

Figure 3. In vitro release profiles of Pts-NP-loaded stents. control, (o) TP l h, ( $\nabla)$ TP $3 \mathrm{~h}$
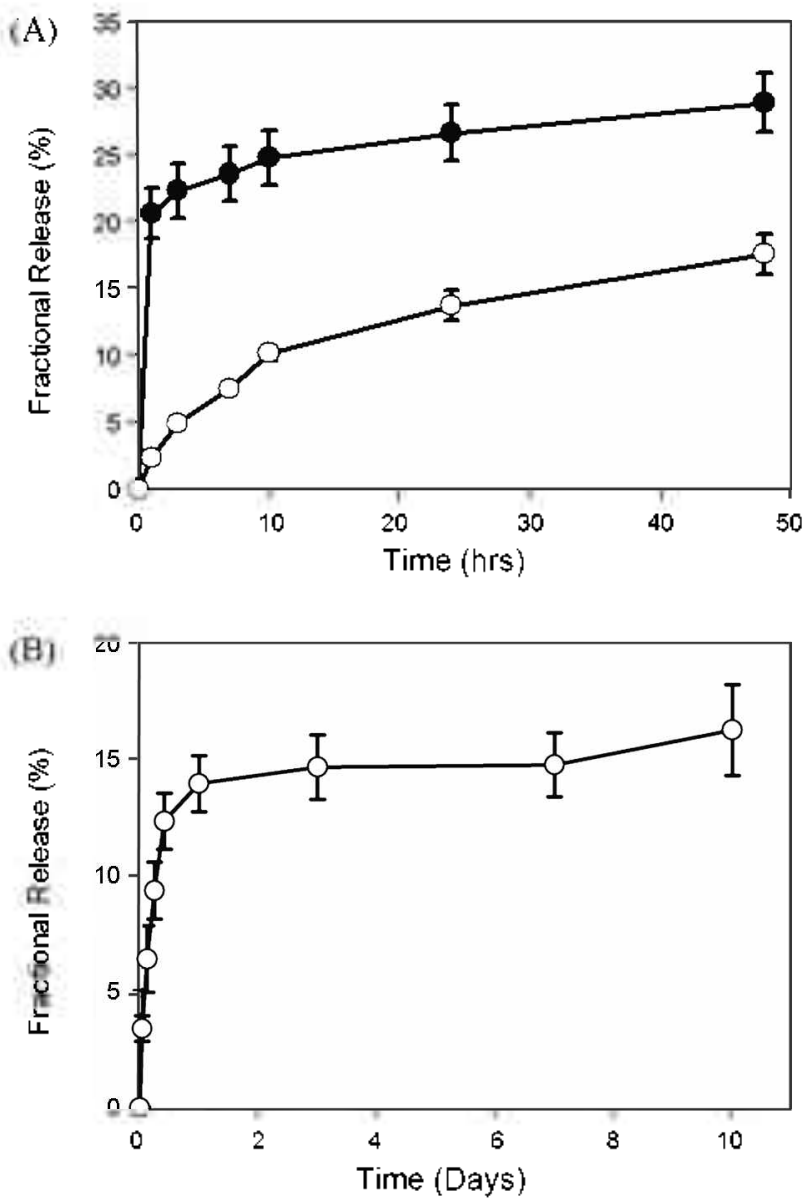

Figure 4. In vitro release profiles of PtX-loaded stents. (•) film-coated, (a) NP-loaded-TP l h.

adjacent to the neighboring particles. However, the nanoparticle layers themselves were different from coated films. The film-coated stents were prepared by a dipping method with the same paclitaxel / PLGA ratio of the paclitaxel-loaded nanoparticles. As shown in Figure t. the nanoparticle-loaded stents released paclitaxel more slowly than the film-coated stents.

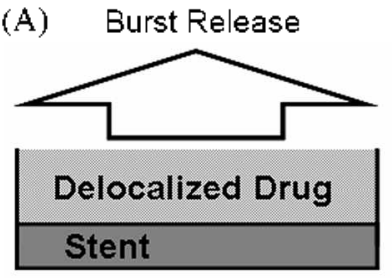

(B) Controlled Release

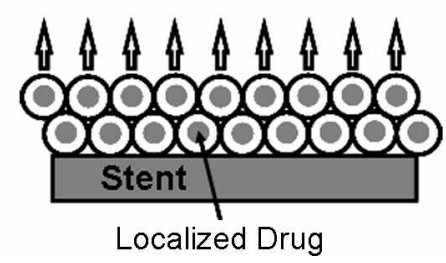

Figure 5. Drug distributions and release patterns. (A) film-coated stents, (B) NP-loaded stents.

The release profile of the film-coated stents had an initial burst. Approxintately $20 \%$ of the loaded paclitaxel streamed out during the first one hour. The nanoparticle-loaded stents. on the other hand. have no initial burst and release paclitavel at the controlled rates. The controlled release patterns may be due to the different distribution of paclitavel (Figure 5). Paclitaxel was spread over the whole films and exposed at the surfaces in the case of the film-coated stents. The exposed paclitavel would flood out in the early release time in an initial burst so that the film-coated stents could not exhibit the controlled release profiles. In the case of the nanoparticle-loaded stents. paclitaxel would be localized at the core of the PLGA nanoparticles and sheltered in the polymer barriers. ${ }^{3-}$ The release rates of paclitaxel would be controlled by the polymer barriers, resulting in the controlled release.

The most important conditions for this controlled release are the temperature and the humidity of the thermal process. The release pattern is constructed by the delocalization of the drug molecules and the shielding of the polymer nanoparticles. and so the characteristics of the polymer nanoparticles must be maintained after the reinforcement of the mechanical strengths such as the thermal process. If the morphologies of the polyner particles are destroyed by melting. it leads to remarkably reduced results with an effective decrease of the drug-delocalization and the shielding by the shells of the polymer namoparticles. PLGA was. therefore. the suitable poly mer for the nanoparticle deposition and the mechanical strength reinforcement by the thermal process which was proved by the SEM inages (Figure $2 \mathrm{C}-\mathrm{E}$ ). The drug release profiles (Figure 4) also confirmed the controlled release effects of this strategy. the deposition of the paclitaxel-loaded PLGA nanoparticles and the thennal process. for the paclitaxel delivery and release.

\section{Conclusion}

The mechanical strengths of the PLGA nanoparticle layers on stents were improved enough for PTCA operations by the simple thennal process. The paclitaxel release patterns of nanoparticle-loaded stents showed controlled release characters. comparable with film-coated stents. This technique gives rise to a new range of applications for nanoparticles and drug-eluting stents.

Acknowledgments. The authors acknowledge the KOSEF S\&T graduate scholarship (J. Joo and S. H. Nam) 


\section{References}

1. Unger, F. Cor: Emopaeun 1999, 7, 128

2. Gruntzig, A. R.; Senning, A: Siegenthaler, W. E. N. Engl. J. Med. $1979,301,61$.

3. Semuss, P. W.; de Taegere, P.; Kiemeneij, F.; Macaya C.: Rutsch, W.; Herndrickx, G.; Emanuelsson, H.: Marco, T.: Legrand, V.; Mateme, P:; Belardi, T.; Sigwart, U.; Colombo, A.: Goy, J. J.; van den Heuvel, P: Delcan, I:; Morel, M: for the Benestent Study Group. N. Engl. J. Med. 1994, 331, 489.

4. Fischman, D. L.; Leon, M. B.; Baim, D. S : Schatz, R. A.: Savage, M. P; Pem, I.; Detre, K.; Veltri, L.: Ricci, D.; Nobuyoshi, M.; Cleman, M: Heuser, R: Almond, D. Teirstein, P. S.: Fish, R. D: Colombo. A.: Brinker, J.: Moses. I.: Shakinovich. A.: Hirshfeld, I. Bailey, S; Ellis, S; Rake, R.; Goldberg, S.; for The Stent Restenosis Study Investigators. N. Engl. J. Afed. 1994, 331, 496.

5. van der Hoeven, B. L.: Pires, N. M M: Warda H. M: Oenrawsingh. P. V: van Vlijmen, B. I. M.: Ouax, P. H. A: Schalij, M. I: van der Wall, E. E.; Jukema, J. W. Int. J. Cantiol. 2005, 99, 9.

6. Sousa, T. E. : Senuys, P. W.: Costa, M. A. Cinculation 2003, 107, 2274

7. Grube, E.; Silber, S.: Hauptmann, K. E.; Mueller, R.: Buellesfeld, L.: Gerckens. U.: Russell. M. E. Circilation 2003, 107, 38.

8. Regar, E.: Semuvs, P. W: Bode, C.; Holubarsch, C.; Guemonprez, I. L.: Wijns, W.; Bartorelli, A.; Constantini, C.; Degertekin, M.; Tanabe, K.; Disco, C.: Wuelfert, E.: Morice, M. C.: on behalf of the RAVEL Study Group. Cinculation 2002, 106, 1949.

9. Sousa, J. E.; Costa, M. A.; Abizaid, A. C.; Rensing, B. J.; Abizaid, A. S.; Tanajura, L. F.: Kozuma, K: van Langenhove, G.: Sousa, A. G. M. R.: Falotico, R.; Jaeger, J.: Popma, I. J.: Serruys, P. W. Circulation 2001, 104. 2007.

10. Bertrand, O. F.; Sipehia, R.; Mongrain, R.; Rodés, T.; Tardif, J.; Bilodeau, L.; Côte, G.: Bourassa, M. G. J. Ann. Coll. Cartiol. $1998,32,562$

11. Konnowski, R.: Hong, M. K.: Tio, F. O:- Bramwell, O.: Wu, H.: Leon, M. B. J.Am. Coll Candiol 1998, 31, 224.

12. Duda, S. H.; Poerner, T. C.: Wiesinger, B.: Rundback, T. H.; Tepe, G.; Wiskirchen, I. Haase, K. K. J Iasc. Intert: Radiol.
2003, 14, 291

13. Woods, T. C.; Marks, A. R. Amm. Rev Med. 2004, 55, 169

14. Moses, J. W.: Kipshidze, N.: Leon, M. B. Am. J. Cardiorasc Dings 2002, 2, 163 .

15. Huizing. M. T.: Misser. V. H.: Pieters. R. C.: ten Bokkel Huinink, W. W. Veenhof, C. H.; Vermorken, J. B.: Pinedo, H. M.; Beijnen, I. H. Cancer Invest. 1995, 13,381

16. Nám, H. Y.: Kim, D. J.: Lim, H. J.: Lee, B. H.: Báek, I. S.; Park, T. S. Bull. Koreon Chem. Soc. 2008, 29, 422

17. Rowinshy, E. K.; Donehower, R. C. N. Engl. J. Hed. 1995, 332 , 1004

18. Farb, A.; Heller, P. F.; Shroff, S.; Cheng, L.; Kolodgie, F. D.; Carter, A. T.; Scott, D. S.; Froehlich, J.; Virmani, R. Circulation 2001, 104. 473

19. Drachman, D. E.; Edelman, E. R.; Seifert, P.; Groothuis, A. R.; Bomstein, D. A.: Kamath, K. R.: Palasis, M. Yang D: Nott, S. H.: Rogers, C. J. Am Coll Cardiol 2000, 36.2325

20. Brannon-Peppas, L. Iht. J. Pham 1995, 116, 1

21. Tain, R. A. Biomaterials 2000, 21, 2475

22. Yamaguchi, Y; Takenaga, M.; Kitagáwa, A: Ogáwa, Y:; Mizushima, Y.; Igarashi, R. J. Control Release 2002, 81, 235.

23. Nam. S. H.: Nam, H. Y. Too, I. R.: Baek. I. S.: Park. T. Bull. Korean Chem. Soc. 2007, 28, 397.

24. Panyam, J: Labhasetwar, V. Adr. Divg Deliv. Rev. 2003, 55, 329.

25. Florence, A. T. Pham. Res. $1997,1+, 259$

26. Aprahamian, M.; Michel, C.; Humbert, W.; Devissaguet, I. P:, Damge, C. Biol Cell 1987,61,69.

27. Opperheim, R. C.; Stewert, N. F.; Gordon, L.; Patel, H. M. Drug Dev Ind. Pham. 1982, 8,531.

28. Westedt, U.; Kalinowski, M:- Wittmar, M.; Merdan, T.; Unger, F.; Fuchs, J.: Schaller, S.; Bakowsky, U.; Kissel. T. J. Control. Release $2007,119,41$

29. Kushwaha, V; Bhowmick, A.; Behera, B. K.: Ray, A. R. Aitif. Cells, Blood Substit. \& Immobil. Biotechnol. 1998, 26, 159.

30. Ioo, T.: Nam. H. Y.: Nám. S. H.: Baek. I.: Park. T. Bull. Korean Chem. Soc. 2009, 30, 1085

31. Prevo, B. G.: Velev, O. D. Langmmir 2004, 20. 2099

32. Feng, S. S.; Huang, G. J. Commol. Release 2001, 71, 53. 